\title{
Mobile Distance Learning with PDAs: Development and testing of pedagogical and system solutions supporting mobile distance learners
}

\author{
Torstein Rekkedal and Aleksander Dye \\ The Norwegian School of Information Technology and NKI Distance Education \\ Norway
}

\begin{abstract}
The article discusses basic teaching-learning philosophies and experiences from the development and testing of mobile learning integrated with the online distance education system at NKI (Norwegian Knowledge Institute) Distance Education. The article builds on experiences from three European Union (EU) supported Leonardo da Vinci projects on mobile learning: From elearning to m-learning (2000-2003), Mobile learning - the next generation of learning (20032005), and the ongoing project, Incorporating mobile learning into mainstream education (20052007).
\end{abstract}

Keywords: Distance learning; mobile learning; learning management systems; LMS

\section{Introduction}

The article discusses NKI basic philosophies of distance learning and their consequences for development of a learning environment supporting mobile distance learners. Most NKI courses are not designed to function as online interactive e-Learning programmes, although some parts of the courses may imply such interaction with multi-media materials, tests, and assignments. NKI courses normally involve intensive study, mainly of text-based materials and includes problem solving, writing essays, submitting assignments, and communicating with fellow students by email or in the Web-based conferences. This means that most of the time the students will be offline when studying. From experience, we know that students often download content for reading offline and print content for reading on paper.

When developing system solutions for mobile learning, it is assumed that the NKI students will have access to a desktop or laptop computer with an Internet connection. This means that when students are mobile and wishing to study, the equipment and technologies they use will be in addition to they equipment use at home or at work. It should also be noted that the solutions 
Mobile DL with PDAs: Development and testing of pedagogical and system solutions supporting mobile distance learners

Rekkedal \& Dye

developed were based on the absolute assumption that mobile learners would study within the same group of students who do not have access to mobile technology. Thus, the design of the learning environment must efficiently cater to both situations and both types of students.

During the first project, NKI developed solutions for mobile learning applying mobile phones and Personal Digital Assistants (PDAs) with portable keyboard. Learning materials were developed mainly for downloading to the PDA and off-line study, while online access to forum discussions, responding to forum messages, reading in forums, communication with fellow students and tutors, and submitting assignments, were handled online via mobile equipment when students were on the move.

During the second project, NKI developed and tested solutions for an 'always online multi-media environment' for distance learners based on the use of PDAs with access to wireless networks. During this project, NKI first developed one specific course for mobile access with PDAs. Cost and efficiency considerations, however, required server-side solutions that made access independent of devices on the user-side. Thus, during the second year of the second mobile learning project, NKI installed software and solutions which, in principle, made all online courses accessible independent of devices on the receiving side - e.g., most types of pocket PCs, PDAs, and mobile phones.

One of the main challenges concerning the use of mobile devices was to find acceptable solutions adapted to the small screen. There is simply not enough space on a small screen for all the information found on a traditional webpage. Another problem encountered was the limited data transfer rate and processing power found in mobile devices. When people use a mobile device with Internet connectivity, the connection speed is traditionally lower than, for instance, that of a traditional mobile phone. Thus, the project tried out solutions designed for a future, as we believe it might be, with online high speed access wherever the student is located.

The aim of the third and present project is to develop mobile learning course content and services that will enter into the mainstream and take mobile learning from a project-based structure and into mainstream education and training.

The article presents and discusses the student experiences from the first two trials of mobile learning and their consequences for further developments within an online distance learning system.

Although it is difficult to foresee what will be the technical solutions for mobile devices in the years to come, there is no doubt that the research on mobile technology in online distance learning at NKI has inspired developments that also increase the quality of our online distance learning in general, helping make us better prepared to serve mobile students now and in the future, independent of which technology students prefer to use when on the move.

\section{Context}

NKI Distance Education is the largest distance teaching institution in Norway, recruiting 7,00010,000 students every year. NKI Distance Education is one unit in the NKI group, a nongovernmental educational institution offering full-time and part-time training on secondary and tertiary level. 
NKI Distance Education was one of the first institutions worldwide to offer online distance education when, in 1987, we started the first trials on our in-house developed Learning Management System, EKKO (Norwegian acronym for "electronic combined education”). Since then, online education has continuously been offered to increasing numbers of students. At time of writing, NKI has approximately 9,000 active online students, studying one of more than 80 study programmes or over 400 courses offered on the Internet/ Web. Since 1987, NKI online distance education has had 60,000 course enrolments. In 2001, we launched what we consider to be the fourth generation online distance education system at NKI: the internally developed Learning Management System (LMS) called Scalable Educational System for Administration and Management or SESAM, a solution which totally integrates NKI's Web-based LMS with its overall Student Administration System and a number of other applications designed for the efficient operation and administration of the logistics and student support measures in online distance education (see Figure 1). We consider the total integration of distance education information technology systems as one major prerequisite for operating an efficient and effective large-scale distance education system. A description of SESAM and its functionalities has been given by Paulsen, Fagerberg, and Rekkedal (2003).

Figure 1. NKI’s integrated systems for online administration and student support.

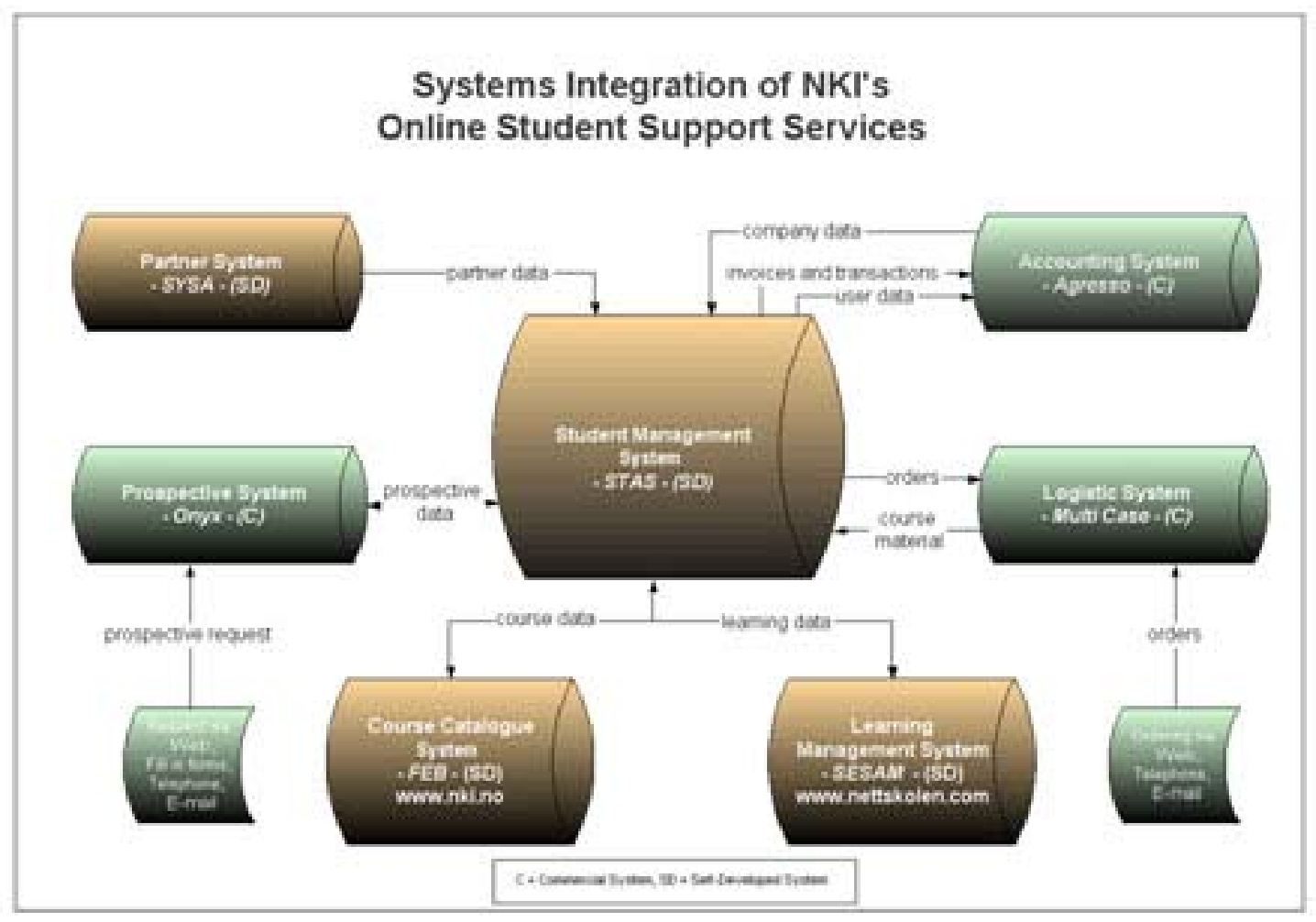

When engaging in the EU Leonardo da Vinci m-Learning projects, the NKI research and development group was very clear that our aim would be to develop solutions that increase access and flexibility, and refine the total distance learning environment to meet the needs of the 'mobile distance learner.’ 
Mobile DL with PDAs: Development and testing of pedagogical and system solutions supporting mobile distance learners

Rekkedal \& Dye

\section{NKI's Basic Philosophies Concerning Distance Learning}

\section{Increasing the flexibility of distance education}

A number of evaluation studies among distance and online learners at NKI have demonstrated that students emphasize flexibility (Rekkedal 1990; 1998; 1999; Rekkedal \& Paulsen, 1997).

We have argued that distance education generally seems to develop in two quite different directions. The solution at one end of the flexibility continuum can be described as an individual, flexible solution that allows students the freedom to start at any time and follow their own progression according to their personal needs for combining studies with work, family, and social life: This solution is called 'the individual flexible teaching model.' This model represents a development of the generic model of distance teaching institutions and normally applies media and technologies independent of time (and place), such as asynchronous computer communication, and pre-produced video, audio, and printed materials. The model on the opposite end of the flexibility continuum, which is called 'the extended classroom model,' assumes that the students are organised into groups that are required to meet regularly at local study centres and applies technologies such as video conferencing, satellite distribution, radio, and television (Gamlin, 1995).

In this connection, we have chosen the philosophy for the development of Internet-based education at NKI: flexible and individual distance teaching with the student group as social and academic support for learning. Each year, NKI recruits nearly 10,000 students to more than 400 courses and over 130 study programmes by correspondence-based and Internet-based distance teaching. In 2006-2007, approximately 70 percent of NKI students choose online study. Students can enrol in any course or programme or combination of courses anytime and progress at their own pace. This flexibility does not exclude group-based solutions in cooperation with one single employer, trade organisation, or local organiser, nor individual students on their own initiative, or by the initiative of their tutor, are collaborating on learning tasks. According to the NKI philosophy on online learning as expressed in the strategic document (NKI, 2005): "NKI Distance Education facilitates individual freedom within a learning community in which online students serve as mutual resources without being dependent on each other" (translated from Norwegian, p. $6)$.

Faced with the challenge of supporting distance students within a flexible distance learning context wherein they must identify and invite fellow students to become their 'learning partner,' NKI has developed different kinds of social software solutions within the LMS-system. As such, all students are urged to present themselves in ways that invites social interaction for learning purposes. This information may be open to all - e.g., members of the learning society of NKI Distance Education, to fellow students studying the same programme, or to tutors and administration only. Student lists contain information about where individual students live and which module they are studying at any given time. Software solutions for inviting and accepting learning partners and for establishing connections have been developed in parallel to the research on mobile learning (Paulsen, 2004). There is no doubt that mobile technology may increase possibilities for efficient interaction between distance students, making them more independent of time and space. The potential of social software for developing solutions that allow students within 'maximum freedom and flexibility' modes of distance learning to engage in cooperative learning activities has been presented by Anderson (2005). 
Mobile DL with PDAs: Development and testing of pedagogical and system solutions supporting mobile distance learners

Rekkedal \& Dye

\section{Views on knowledge and learning}

When we started our first discussions on m-learning and planning for the first m-learning solution development, it was very clear that the learning aims, content, and teaching/ learning methods in the NKI online courses and programmes were, for the most part, very different from most eLearning courses, which are typically designed with self-instructional programmed learning materials (Dichanz, 2001).

To us, learning results in a change in students' perception of reality related to the problem areas under study. Learning also results in students' increased competence in problem-solving, ability to differentiate between focal and more peripheral questions, and increased analytical skills and competence in using various tools within a field, in appropriate ways. This means that learning results in qualitative changes taking place in students' understanding, academic, social, and technical competence. Learning is a result of students' active processing of learning material and solving problems individually and/ or in groups. This view is different from what often we find in many so-called e-Learning programmes, wherein 'knowledge' often is seen as providing students a large amount of information and testing their ability to recall and reproduce facts. In addition to cost considerations, this is why NKI has generally placed little emphasis on developing interactive programmed learning courses or modules based on a tradition more related to behaviouristic pedagogy and knowledge transmission (see Marton, Dahlgren, Svensson, \& Säljö, 1987; Marton, Hounsell, \& Entwistle, 1997; and Morgan, 1993; on students' conceptions of learning, deep level, and surface level approaches to learning). We also hold the view that learning is an individual process that can be supported by adequate interaction and/ or collaboration in groups (Askeland, 2000), a viewpoint that is stated in the NKI strategic plan (2005).

From the discussion of NKI philosophy of learning, views on knowledge, and aims and objectives in formal studies, we came to the conclusion that we should experiment with mobile learning based on more advanced technology than what was available on mobile phones in 2001, the WAP and Smart phones. Thus, we found that the Compaq iPAQ PDA in combination with mobile phone communication was suitable for our purposes. Our experiences, combined with the experiences of other project partners (Fritsch, 2002) during the first project, resulted in continuing the developments of mobile learning with PDAs in further m-learning projects.

Our main objective in the first m-learning project was to extend the distribution of learning materials and communication to lighter equipment, specifically PDAs and mobile phone. During the first project, we understood that for NKI, our long-term challenge would be to develop a system and server-side solution that presented learning materials in ways suitable for PDA and other mobile technologies. We also had to determine acceptable solutions for access to, and interaction with, NKI learning materials and for teacher-to-student, student-to-teacher, and student-to-student communication. We should also add at this juncture, that parallel to the mlearning projects, NKI was also engaged in projects aimed at developing universal accessibility of distance learning (Mortensen, 2003), which, it should be noted, has similar consequences concerning server-side solutions for making content available to anyone independent of physical handicaps or technology on the receiver-side.

Our aim in designing the environment for the mobile learner was to extend, enhance, or arguably even restore, flexibility that should be inherent in distance education. Indeed, to a great extent, the flexibility aspects of distance education took a step backwards when we converted from paper- 
Mobile DL with PDAs: Development and testing of pedagogical and system solutions supporting mobile distance learners

Rekkedal \& Dye

based to online learning, making a situation wherein students were oftentimes required to study at a place (and at a time) where a computer with access to the Internet was available. This aim was still in focus during the second and third m-learning projects.

By trying out the didactic and system solutions with different types of students in different settings, we studied the results and effects of the developments of mobile learning solutions in the two first projects. Students' opinions and experiences concerning mobile learning were assessed through our use of structured interviews. As well, because of our need to make comparisons with project partner experiences, formal questionnaires containing the same questions to students studying in different mobile learning environments in other European countries were applied.

\section{Designing and Testing the Environment for Mobile Learners in the Project, 'From e-learning to m-learning'}

\section{Studying online and offline}

In line with the above discussions on learning and studying, most NKI courses are not designed to function as online interactive e-Learning programmes, although some parts of the courses may imply such interaction with multi-media materials, tests, and assignments. NKI courses normally involve intensive study mainly of text-based materials that requires students to solve problems, write essays, submit assignments, and communicate with fellow students via email or during Web-based conferences. This means that most of the time NKI students will be offline when studying. From experience, we also know that students often download content for reading offline and print-out content for reading on paper.

\section{Technical solution}

It should be emphasized that we assume that NKI distance education students will have access to a desktop or laptop computer with an Internet connection. This means that the equipment and technologies students use when mobile are, in fact, 'additions' to the equipment they normally use when studying at home or at work. It should also be noted that our developments were based on the absolute assumption that NKI's mobile learners would be studying with students who do not have access to mobile technology. Thus, the design of the learning environment had to cater efficiently to both learning contexts.

When planning for the m-learning environment of the first project, the NKI project team engaged in long discussions on whether to develop the learning materials for online or offline study. Given the above experiences, coupled with cost considerations concerning mobile access to online learning materials, we concluded that the learning environment for the first course should include the following aspects (Fagerberg, Rekkedal \& Russell, 2002; Rekkedal, 2002a):

\section{Technology}

- Pocket PC/ PDA

- Mobile phone

- Portable keyboard 
Mobile DL with PDAs: Development and testing of pedagogical and system solutions supporting mobile distance learners

Rekkedal \& Dye

\section{Learning content and communication}

Learning content to be downloaded to the mobile device could be studied offline, if the student so desires. Downloaded content included all course materials, such as:

- Content page

- Preface

- Introduction

- All study units

- $\quad$ Resources (articles on the web, references to other resource materials)

- Online access to the discussion forum, with capacity that allows students quick access to readings in the forum, and writing and responding to contributions made in the forum

- Email with capacity that allows students to communicate with tutors and fellow students, and for submitting assignments either as text-based emails or as Word or Text attachments

\section{Students' and tutor's use of technology when mobile}

When mobile - and using mobile technologies - we found that it was generally satisfactory for students (and tutors) to have the course content available to study on the PocketPC. In addition, when mobile, students must be able to:

- Access the course forum to read archived messages (if necessary). Messages on the forum were also emailed to participants

- Access their course forum to submit their contributions to the course discussions

- Send email to fellow students, their teacher, and to administration (i.e., study advisor)

- $\quad$ Receive email from fellow students, their tutor, or from administration

- Submit their assignments by email, including attachments

- Receive assignments back from their tutor, corrected and commented on, as attachments

To access email and discussion forums, mobile phones with infrared connection to the PDA were used.

\section{Trial of two Project 1 courses}

The first project two courses were tested and evaluated with students using mobile phones and PDAs. The two courses were: The Tutor in Distance Education (Norwegian version of the introductory course for tutors); Online Teaching and Learning (Master level course 5 ECTS credits). 
Mobile DL with PDAs: Development and testing of pedagogical and system solutions supporting mobile distance learners

Rekkedal \& Dye

The first course, comprising nine $(n=9)$ students, was a simulated distance teaching setting. The second course, comprising three $(n=3)$ students studying with other students not using mobile technology, was trial of a 'real setting' - a context expected to be the normal situation for mobile learning in NKI's distance education setting. In both cases, technological evaluations were carried out using qualitative methods employed in field research models. The first course was a trial designed to evaluate the use, functionality, and acceptance of the technology. The researcher functioned as tutor and used the course to test and evaluate its mobile learning aspects. Rather than asking subject related questions in connection with assignments and forum discussions however, the researcher instead asked students questions related to the technology itself. The educational background of the nine students taking the first course ranged from two associates degrees to $\mathrm{PhD}$; the age of participants ranged from 24 to 56 years. All participants were competent in the use of information technologies.

The second course was administered in a normal study setting, and the researcher had access to the course forum and carried out the evaluation by asking participants questions on the use of the technology, while another tutor was teaching of the course. This test course had five $(n=5)$ registered students: four in Norway and one in Canada. Three of the Norwegian students used mobile devices (mobile telephone and PDA with a foldable keyboard). The three "mobile learners" included one man (age 32, with a Bachelor degree in computer science) and two women (the first, age 55, with a $\mathrm{PhD}$ in Chemistry and working as webmaster, and the second age 35, with a Bachelor of Education and director of studies at a technical research centre). Both questions and answers on mobile learning were distributed as contributions to the course forum.

In addition to the open qualitative questions given during the study, students in both trials answered a questionnaire consisting mainly of statements to be answered on a 5-point Likert scale. The questionnaire was used as part of the common evaluations in the international project. For our purpose, the qualitative evaluation was found to produce the most relevant and valid data.

\section{Main Conclusions: Project 1 trials}

We learned that downloading and synchronizing learning materials to the students' PDAs caused few (if any) problems. The learning content was delivered in two versions: HTML and Microsoft Reader e-book format. As students' preference for the e-book format was evident from the results of first trial course, the second course applied e-book materials only. During the first trial course, we found that figures and illustrations were hard to read on the PDA. Taking notes was also a problem. Therefore, for the second trial, we equipped students with keyboards, which resolved these problems and enabled students to write longer texts in connection with assignments. Using mobile phones to submit assignments and respond to the course forums was found to be fairly easy, with few problems encountered. Costs were also acceptable, but only on the condition that students produced their lengthy texts offline before sending them.

Our main aim in designing solutions for mobile learners was to support and maximize students' freedom to study with increased flexibility. This supports findings in previous trials, which shows that the main advantage of m-learning (as designed in these trials) is that it increases flexibility for students studying at a distance (Rekkedal, 2002b; 2002c). 
Mobile DL with PDAs: Development and testing of pedagogical and system solutions supporting mobile distance learners

\section{Rekkedal \& Dye}

Figure 2. The picture on the left shows a tutor 'on the move,' writing and sending emails to his students from Düsseldorf 'Himmelturm.' The next picture is of a student on holiday communicating from the garden of his hotel in Rome.
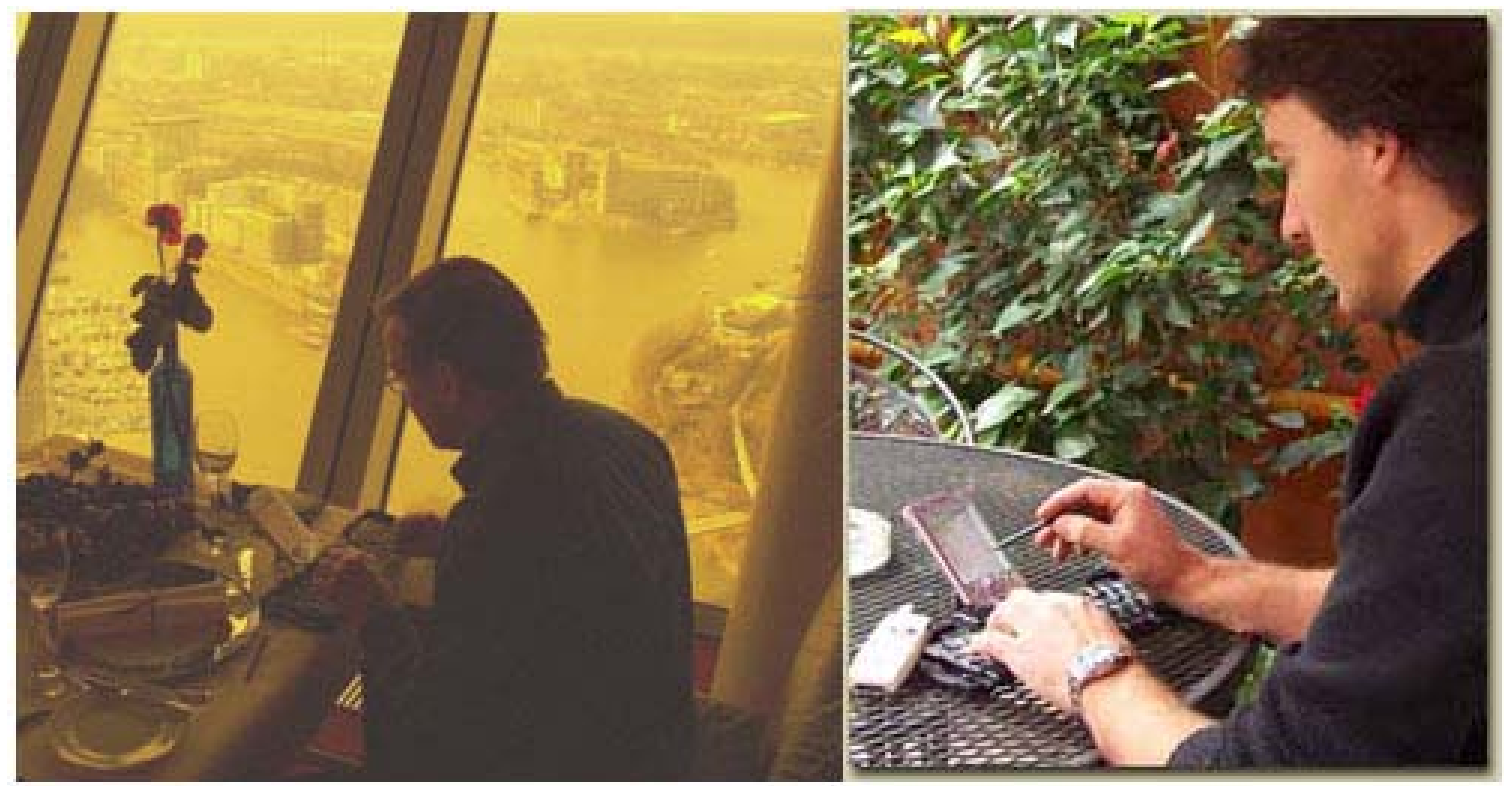

\section{Designing and Testing an Always Online Environment for Mobile Learners in the Project 'Mobile Learning: The next generation of learning'}

Based on the results and our experiences gained from the first project, NKI continued its research on m-learning, this time based on the PDA solutions that were available in 2003-2005. After examining the different brands available, we decided to develop solutions for the HP iPAQ Pocket PC 5500 series with a built-in wireless network card. Again, all developments were undertaken with the main objective of developing generic solutions.

For NKI, a large-scale provider of flexible online distance learning, it is extremely important to deliver cost-effective solutions. For instance, we needed to find system solutions that suited the needs of mobile learners in addition to students who wish to study using more standard technologies, such as desktop PCs. Any solution must be designed in ways to allow both groups to participate in the same course. In other words, we had to find optimal solutions for communication and for distributing course content, independent on whether students and tutors choose to use mobile technologies or standard desktop PCs.

When planning the first m-learning project, we determined online access to course content to be the best solution to meet NKI's needs. However, when we started researching the first m-learning project, it was neither technologically nor economically feasible to provide continuous online access. By 2004, however, technological advancements where such that they allowed us to start developing and experimenting with solutions based on the notion that students had access to an 'always-online mobile learning environment.' Today, the 'always online' mobile learning environment is almost a reality and will likely be the norm in the near future. 
Mobile DL with PDAs: Development and testing of pedagogical and system solutions supporting mobile distance learners

Rekkedal \& Dye

\section{Provisional Developments during Year 1 of the Project}

The NKI project team committed itself to develop one standard NKI course, Sales and Services, to an 'always-online mobile learning environment' during the first year, and a second course, Administration Systems and Support Services for Online Education, during the second year.

The first course, Sales and Services, was developed with an additional version with specific materials for mobile learners. This version was produced on the server in a format adapted to the PDA screens and multi-media materials specifically developed to be accessed by the PDA. These developments have been described by Dye, Faderberg, and Midtsveen (2004).

Figure 3. Screen shot from a PC of the specific version of the course, Sales and Services.

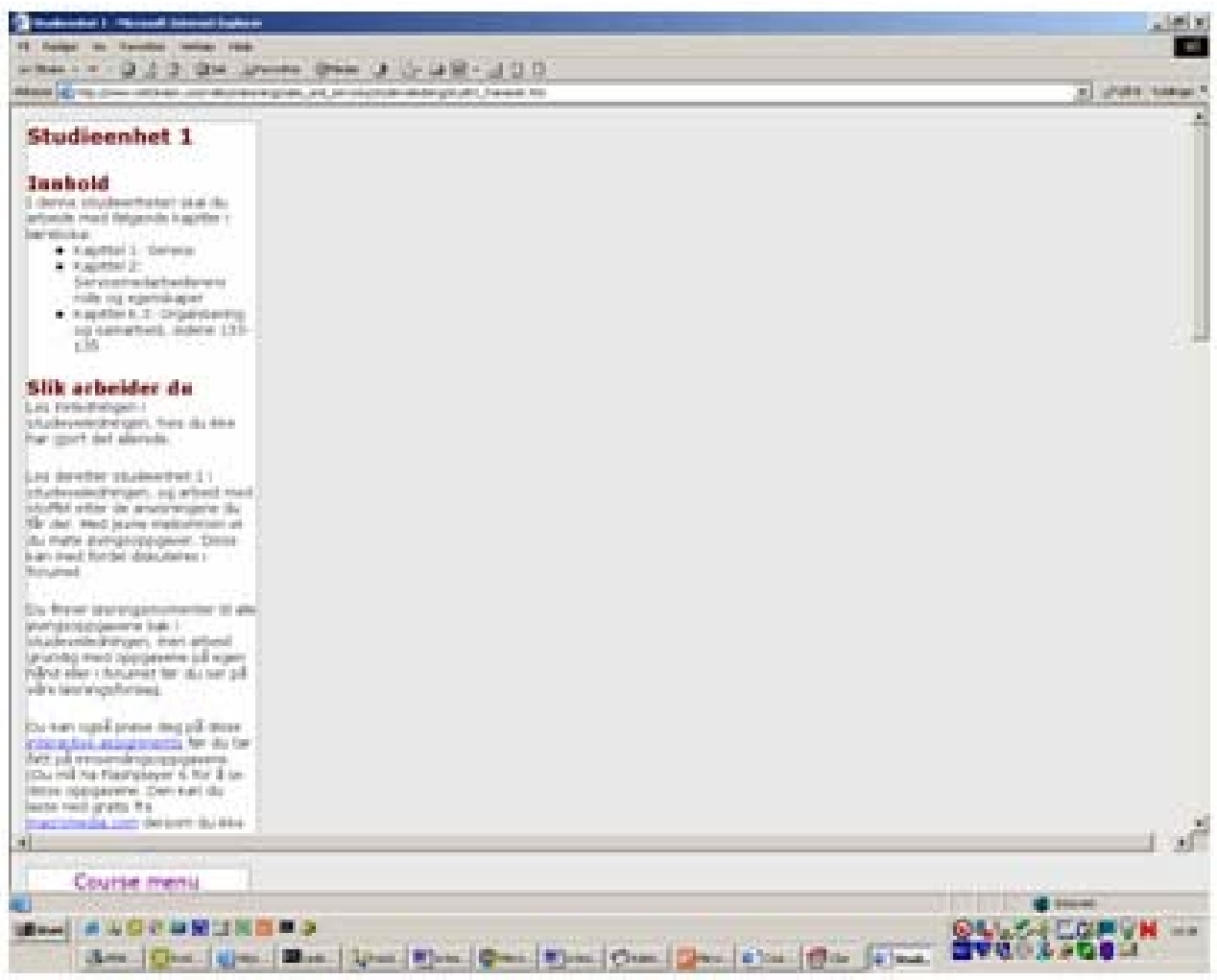

We found that the text used was perfectly adapted to the PDA's screen. For ease of navigation, the menu link was fixed at the bottom of the PDA's screen. Multi-media elements were also developed using Macromedia Flash. We designed and tried different solutions to ensure that the multi-media elements were readable on the PDA, but we really did not arrive at any good solutions. Our conclusion, both during development and beta testing with students, was that most multi-media elements included details, which were very difficult read on the PDA. We also found that it was more useful focus our efforts on the readability of text versus the background colour combinations. We found that the choice of font was also important. For example, below are two screens shots of assignments on the PDA (in Norwegian). 
Mobile DL with PDAs: Development and testing of pedagogical and system solutions supporting mobile distance learners

Rekkedal \& Dye

Figure 4. Screen shots from the PDA of multi-media multiple-choice question and 'drag-anddrop' assignment.
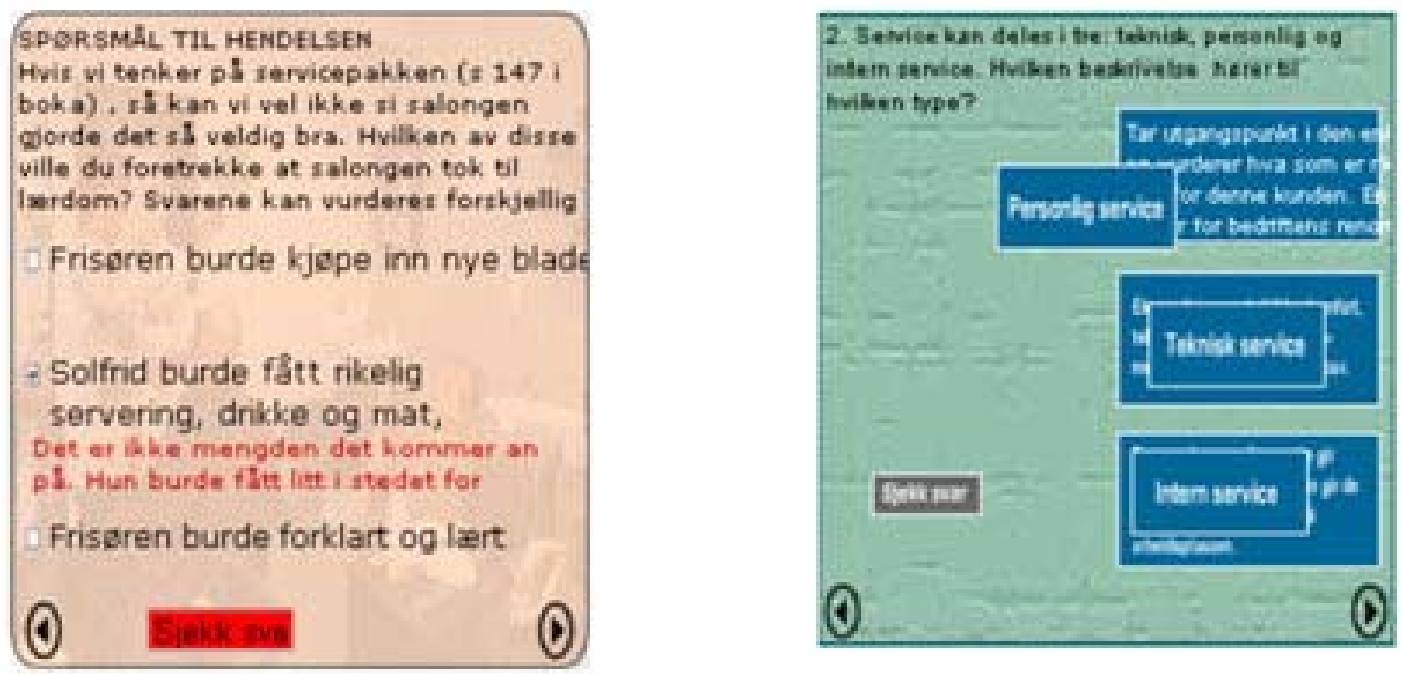

It was clear during internal testing that the solutions functioned according to expectations; they allowed all students in the course, irrespective if they were mobile or tied to a desktop computer, to participate and communicate in the same course. However, because additional materials had to be developed specifically for the mobile learners, we found that these solutions could never be applied cost-effectively on a large scale.

\section{Second Year Functionalities of the 'Always Online Environment' Developed by NKI in the Project 'mLearning: The next generation of learning'}

When planning for this second project, the project team sought to develop m-learning solutions wherein students and tutors using wireless PDA/ PocketPC could benefit an 'always-online' environment. In the first project, although the downloaded course contents could be accessed any time, some significant disadvantages were found, mainly that:

- Participants in the course often lacked incentive to log into the Internet College to take advantage of the larger learning community

- Participants had no access to interactive materials

- $\quad$ Participants encountered low - or no - access to other Internet resources

- Participants were restricted in their communication, likely due to costs but also because of having to connect to mobile networks for email, submitting assignments, and contribute to the forum.

During the planning process, we described the following aspects of an 'always-online' solution, which we determined would be necessary to increase the quality of service for those teaching and learning in a mobile environment: 
Mobile DL with PDAs: Development and testing of pedagogical and system solutions supporting mobile distance learners

Rekkedal \& Dye

- Access to high bandwidth networks, which enable faster uploading and downloading of course content and use of streaming audio, video, and advanced graphics

- Mobile technologies that are not tied to and operate independent of students' and tutors' desktop PCs

- $\quad$ Access to the Internet, 24/ 7

- $\quad$ Access to email, 24/ 7

- Access to online assessments, assignments, course activities

- Options that enables group collaboration

- Options that support synchronous communication such as chat and IP telephony

- ADSL or free access to WLAN, needed to make mobile learning affordable

During the first phase of this project, an 'ideal' description of requirements for a mobile learning management system (mLMS) for the NKI context was developed by Dye and Fagerberg (2004). These requirements were based on the assumption that the NKI Learning Management System, SESAM, would be further developed to accommodate the needs of mobile learners using PocketPCs. The specifications proposed by Dye and Fagerberg (2004) are presented below and divided into the following categories:

\section{Overall framework needs}

The mLMS must be a part of an LMS. It must support both the mobile client as well as traditional clients, and it should automatically provide different types of content on different devices. It must also create a comfortable learning environment for mobile learners.

\section{Course content}

The mLMS must be able to archive course content, provide easy navigation, and provide a zoom function for display of illustrations and pictures.

\section{Access to courseware}

The mLMS should provide access to online resources such as libraries, references, glossaries, exams, databases, and to course planning tools and calendars. Students must be allowed to submit assignments, and tutors must be allowed to comment on, and return, students' assignments using mobile devices. Students must have access to a class list with tutor and student information. They should be allowed to answer questions using multiple choices, drag-and-drop test/ exercises, etc. Text-to-speech options (that are available on PCs for all NKI courses) would similarly be very desirable. Further, the mLMS must support graphics, audio and video, moving images, provide access to search engines, and provide capacity for immediate response and feedback. 
Mobile DL with PDAs: Development and testing of pedagogical and system solutions supporting mobile distance learners

Rekkedal \& Dye

\section{Communication}

The system must provide access to online synchronous communication tools such as chat, and to asynchronous communication tools such as email, and Short Messages Service (SMS) to allow for broadly distributed information such as notices on grades and assignments. Multimedia Messaging Service (MMS) should be also supported. Students and tutors must have access to message boards, course forums, and online lists that contain tutor and student information.

\section{Other}

The mLMS should allow for students to enrol in a course online, and provide export features that allow students to access to their course materials offline. Personal settings should be adjustable (i.e., changing passwords or email addresses). The system should provide access to technical support services, frequently asked questions, contact information, general study information such as exam dates, course syllabi and handbooks, regulations, and so forth. A site map should also be provided for easy navigation. Ideally, users should be able to print from their mobile devices and access an area where they can upload and store personal files.

\section{Conclusions from Testing}

During year two of the project, NKI developed SESAM into a functioning mLMS. The mLMS system was beta tested in March, 2005.

The test students were 18 NKI employees registered as regular students in the course, Sales and Services (Dye \& Rekkedal, 2005), seven $(n=7)$ males, and eleven $(n=11)$ females. All had no previous connection to the m-learning project. Ages of the participants ranged from 30 to 60 (10 were between the age of 51 and 60). All had higher education.

The trial was carried out in a sort of laboratory situation, after which the students had the opportunity to study the course for three weeks. The test was administered by two researchers in the project; one researcher functioned as a tutor and the other as an observer. The evaluation was carried out using the same questionnaire with Likert attitude scales, plus some open ended questions used in Project 1 . In addition, the researchers observed the participants, made note of students' viewpoints, and asked students questions concerning their use of the technology in connection with their assignments, forum contributions, and use of email with other students and tutors.

\section{User friendliness}

User-friendliness of mobile learning in the context examined. Nearly all the students reported that they found the equipment easy to use. Some indicated that the "experience was fun." When asked whether or not they would like to take another m-learning course or recommend a m-learning course to others, some students were more reserved, however. We speculate, however, that students' experiences of the trial situation may have influenced their answers, as they did not provide decisive answers. 


\section{Didactic efficiency}

In terms of didactic efficiency, taken the assumed context of m-learning as a supplement to NKI's established distance online learning environment, students in this trial project agreed that "mlearning increases quality," that "objectives can be met by m-learning," that "accessing course content and communication with the tutor was easy," and that "m-learning is convenient for communication with other students."

A majority agreed that "evaluation and questioning" was effective. Again, however, some students in this trial were uncertain and in some cases negative. The negative attitudes of some students may be related to the fact that during the trial phase, some of the test and questioning materials were distributed with graphical materials, which was far from perfectly presented on their PDAs. The students were also exposed to graphical materials specifically developed for the PDA (part of Year 1 developments) and to the standard graphical course materials presented on the PDA. Both types had definitely significant weaknesses. The size of the illustrations specifically developed for the PDA had to be reduced to make the number of details readable on the small screen. Moreover, illustrations were generally too detailed to be easy to read on the small screen.

\section{Technical feasibility}

Most students found navigation easy. They did not agree, however, whether the graphics and illustrations were necessary. More than half of the students in the trial course were uncertain - or disagreed - with the statement that "graphics and illustrations are necessary for m-learning to be effective." We speculate, however, that this finding may partly be based on students' learning context at NKI, which assumes that students would also be accessing their learning materials on standard desktop PCs equipment and that their course work would consist primarily of text-based learning materials.

\section{Cost efficiency}

Most participants agreed that m-learning increases access to learning. Access to technology, however, is still lacking. Mobile phones with more PocketPC-like functionalities may resolve this problem in the near future, however. Previously, we have shown that communication costs, even when communicating by mobile phone, are low. As such, in these trial situations, we assumed that the learning could take place in an 'always-online' environment with free access. For most users today, however, sending emails is still easier to send via their mobile phone than taking the time needed to configure their PDA for sending emails through different network providers.

Students tried synchronous communication both via chat and IP telephony. Based on their experiences in the m-learning test, it generally seemed that they assumed that the chat function would be similar to chatting on an ordinary PC. When questioned, the majority of participants indicated that they believed that the chat function could be useful in m-learning. 
Figure 5. Video on the PDA

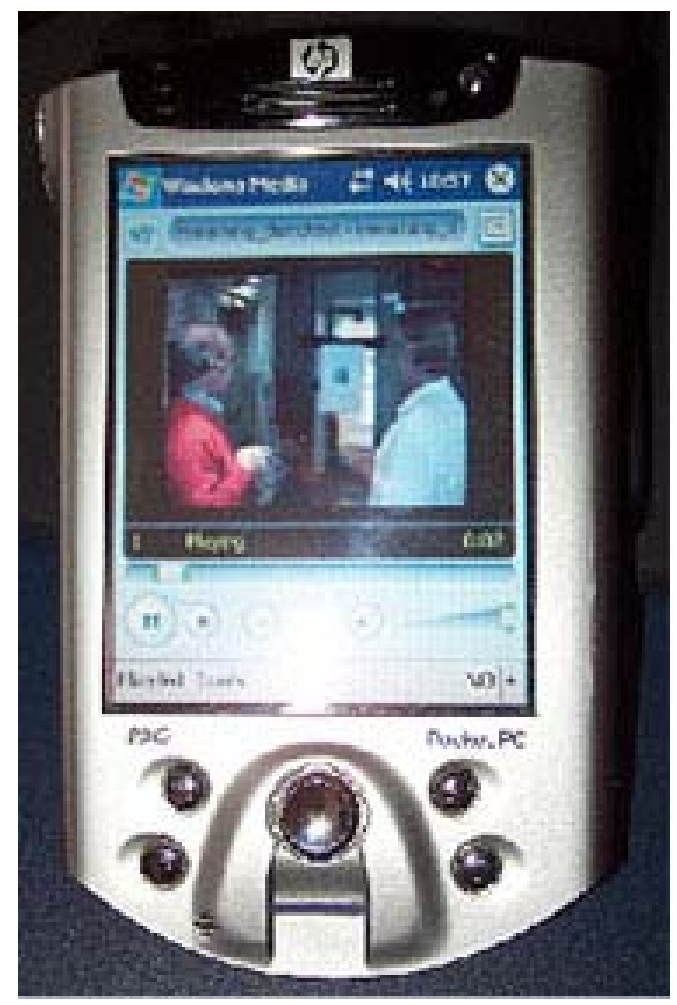

\section{Functionalities and quality}

Video on the PDA using small video clips worked very well using the Windows Media Player. No problems were reported in viewing the picture and audio files, and most participants reported them to be high quality. We did, however, encounter problems when we tried to stream video directly from the Web browser. Unlike Internet Explorer (IE) for a PC, the pocket version of IE is not capable of streaming video directly from the browser; nor can it start the Windows Media Player. This means that users must copy the URL into the Media Player to access and watch the video. While this tactic seemed to work okay, it is clearly a cumbersome way to watch a video. The students' opinions concerning the functionality of the video also differed. It was clear to us, however, that their 'uncertain' and 'negative' responses were related to the difficulties they encountered in playing the video than to the quality of the video itself. In fact, the students in this trial course found the quality of the streamed video to be quite good.

As a result of previous projects working with universal accessibility (Mortensen, 2003), we also tested the use of synthetic speech. We implemented a technology that makes it possible to save the text on a webpage as an MP3 file and have it 'read' afterwards using the PDA. The students reported that they were generally positive concerning the quality of both human and synthetic sound on the PDA - all responding on the positive side of the scale. The quality of both digital human voice and synthetic speech was found to be sufficient.

Generally, participants also indicated that they were generally impressed by the quality of IP telephony on the PDAs. Most agreed with the statement that "IP telephony could be useful in mobile learning." The one participant, however, disagreed with this statement, likely because s/he 
Mobile DL with PDAs: Development and testing of pedagogical and system solutions supporting mobile distance learners

Rekkedal \& Dye

held the position that synchronous communication generally is not useful in distance learning, which, in principle, is fully in-line with the NKI philosophy and strategy premised on asynchronous communication.

According to students functions such as sending and receiving emails, making posts to their course forum, submitting assignments as Word attachments, and receiving tutor feedback on projects, functioned well. There were a few negative responses, however.

Students were generally very positive towards reading text on the PDAs, with the majority holding positive opinions to most of the questions asked concerning the m-learning environment. Despite these positive opinions, however, many indicated to us that they did not find the solutions of sufficient quality for mobile access only. This finding falls in line with our assumptions that mlearning in the NKI online system, should only be seen as an addition to increase access and enhance flexibility.

The students agreed that the 'always-online' mobile solutions increase the flexibility of distance learning. To a large extent, they also agreed that the m-learning solutions increase the quality of course arrangements. More than half of the students, however, reported that they were uncertain as to whether the solutions used in the course trial could actually increase the quality of learning outcomes. This, of course, is a very difficult question to answer based on the experiences from this trial situation.

It was clear that students with a technical background and working in IT-positions were less enthusiastic about mobile learning than students with limited technical backgrounds. According to their statements, this group of students were less tolerant of functions that were more complicated or took longer than similar functions found on standard PC equipment. This could be seen as an indication that the technology still needs to be developed further before it will be attractive enough for online learners in general. The research undertaken to date, however, has demonstrated that developing solutions that make courses available in sufficient quality, and independent of devices on the user-side, seems to be a sound strategy.

\section{Incorporating Mobile Learning into the Mainstream of Education and Training}

\section{Introduction}

The project 'Incorporation of Mobile Learning into Mainstream Education and Training' was launched in October 2005 and is projected to end in September 2007. This scope of this project is based on what we learned during the two earlier projects reported in this paper. We now feel it is time to take mobile learning from its project trial status and incorporate more formalized mlearning solutions into mainstream education and training in Europe. It is also time to disseminate the results of our research to interested parties in Europe and around the world.

For NKI, this final project builds on the situation that all online distance courses will be available on PDAs (and also on smart phones with Web-browser capacities) without any need for adaptation for individual courses. As such, during this final project we are seeking to develop services using primarily Short Message Service (SMS) technology to support online distance education within the context of a cost-efficient, large-scale distance education institution. 
Mobile DL with PDAs: Development and testing of pedagogical and system solutions supporting mobile distance learners

Rekkedal \& Dye

Infrastructure for new and additional services must be developed to be applied in all courses, irrespective if they are tied to ordinary PCs or available on mobile devices.

\section{Specification for the project}

The term 'mobile,' as used in the project, includes all types of devices that are connected to the mobile phone system. These devices will include capacity for voice communication, and in many cases, SMS and Multimedia Message Service (MMS) messages. Advanced versions of these devices will include Wireless Application Protocol (WAP), a secure specification that allows users to access online information instantly (i.e., send and receive email and surf the Web) via handheld wireless devices such as mobile phones and smart phones.

\section{Mobile technologies can be divided into two basic categories}

Push: MMS and SMS are the two leading push technologies for mobile devices. SMS functionality is available on nearly all mobile phones in use today, thus making it the most robust platform for push technologies for communications where 'guaranteed' delivery is needed. MMS is nipping on the heals of SMS, as it is very, very close to becoming a universal standard as well.

Pull: Key technologies used for pull communication will include WAP, HTML, and email. For optimal use, an analysis of the market penetration of these technologies will be required. As well, a market penetration of JAVA/ Flashlite and other relevant technologies will also be ascertained. The more valuable - or critical - a given service is to students, the more important it will be for students to own and make use of the service. Important/ valuable services will therefore probably be delivered using SMS because of its ubiquitous availability and proven track record of reliability.

\section{Hardware}

To set up a basic infrastructure, a SMS/ MMS gateway is needed, which should include the ability to send and receive SMS/ MMS messages. Received SMS/ MMS messages should be made available to a computer, so that they can be processed either by NKI staff responsible for handling students requests, errors, and so forth. An in-house SMS service will consist of one or more GSM modem terminals, along with software (housed on a server) that enables different devices to 'talk' to the GSM modem terminals, will be needed as well.

\section{Service requirements}

The mobile service development process will start with the smallest and easiest service that will deliver a business function to NKI, which means increasing to quality of NKI's distance education offerings. The next phase will then deal with more complex and advanced services. All services should handle error messages and log them, record costs, and so forth.

As mentioned, NKI will focus its efforts on services that support mobile phones for all online courses and programmes. The first service that will be evaluated is an SMS message, which will include practical information such as 'how-to' log on to the NKI Internet College, how to get a username and password, etc. This SMS message will be sent to new NKI students whom we, for whatever reason, have not been able to reach via email. This SMS message will also include a 
Mobile DL with PDAs: Development and testing of pedagogical and system solutions supporting mobile distance learners

Rekkedal \& Dye

link to 'Learning to Learn,' an introductory course applicable to all online programmes, in that it offers students tips on how to study and what to expect as an NKI student. This will be a lightweight WAP version of the original 'Learning to Learn' course.

We will also use the system to get in touch with students who have registered using invalid email addresses. Our plan is to develop a solution that automatically sends an SMS message to the student if an invalid email address is detected by the system.

\section{Possible services}

There are numerous possibilities for the use of SMS/ MMS services suitable for supporting online distance learners. NKI practices flexible pacing and free start-up times, and has developed advanced support systems to follow-up with students and teachers alike.

The following services might be developed and implemented for mobile technologies during the present project (Russell, 2005):

- Password retrieval for students who have forgotten their password

- Welcome message to students, which includes their user name and password. Included in the 'welcome' could include tips on 'how-to' log on to course webpages. Messages should be stored on mobile phones, and provide links to other services available from mobile devices. The message may also include a question for permission to communicate to the student via mobile phone

- The introductory course Learning to Learn will be designed specifically for delivery to mobile devices, preparing news students on what to expect as an NKI student. We hope to include an introduction on study techniques available for mobile via WAP

- $\quad$ Reminders to students who fall behind their studies

- Reminders to students to register and enroll for exams via mobile phones

- Delivery of interactive quizzes

- Delivery of notification to teachers, indicating that a student has submitted an assignment, and possibly automated follow-ups if the teacher is late in responding

- Delivery of notifications related to assignments and grade posted

- Development of a Web interface that allows teachers and administrators to send SMS messages to students, and allows students to send messages to other students

- Allow students to upload pictures and text to their presentation

- Allow students to upload pictures and text to their blog

- As much of the NKI teaching/ learning site as feasible to be made available to mobile Web browsers 
Mobile DL with PDAs: Development and testing of pedagogical and system solutions supporting mobile distance learners

Rekkedal \& Dye

Because this third project is in its first stage at the time of writing, it is difficult to describe in detail exactly what services will be developed and tested. It is also premature to determine any costs involved to students or NKI, along with this usefulness and general level of acceptance by users.

\section{Conclusions}

NKI's research and development on mobile learning in connection with the three EU Leonardo da Vinci projects have led to better, more flexible mobile solutions needed to serve distance learners studying online. Through trial and error, we have learned that cost-efficiency considerations did not permit us to develop parallel versions of courses. Instead, we found that courses must be developed, presented, and distributed in a manner that allow both mobile and non-mobile distance learners to participate in the same course, using the same course materials that can be accessed from standard and mobile technologies. Moreover, we found that course contents available on mobile devices must be of minimum acceptable quality. Interaction with course content and multi-media materials, as well as communication with tutors and fellow students, must function adequately using both standard and mobile technologies.

The question remains on what the 'ideal' device and solution for mobile learning will look like. In all probability, however, the answer will very likely rest with students' individual preferences. That is why NKI has found it extremely important to experiment with different solutions which, in turn, have inspired further developments in finding the right mix of course design and system solutions that serve the needs of all learners, independent of whether they are using a desktop PC or whether they are using mobile devices.

\section{References}

Anderson, T. (2005). Distance Learning - Social software’s killer ap? Paper to the Open and Distance Learning Association of Australia Conference, Breaking Down Boundaries, Adelaide, November 9-11. Retrieved June 26, 2005 from: http://www.unisa.edu.au/odlaaconference/PPDF2s/13\%20odlaa\%20-\%20Anderson.pdf

Askeland, K. (2000). Fjernundervisning i spenningsfeltet mellom pedagogen og teknogen. In G. Grepperud, \& J. A. Toska 2000 Mål, myter, marked - Kritiske perspektiv på livslang læering og høgre utdanning. SOFF-rapport 1/2000. Tromsø: SOFF.

Dichanz, H. (2001). E-learning, a linguistic, psychological and pedagogical analysis of a misleading term. Paper presented at the 20th ICDE World Conference, April 2001, Düsseldorf, Germany.

Dye, A., Fagerberg, T., \& Midtsveen B. (2004). Technical Working Paper 2004, NKI Distance Education: Exploring online services in a mobile environment. Retrieved June 26, 2006 from: http://learning.ericsson.net/mlearning2/files/workpackage2/NKI technical_workingpaper 2004.pdf

Dye, A., \& Fagerberg, T. (2004). Mobile Learning Management System specification. Retrieved June 27, 2006 from: http://learning.ericsson.net/mlearning2/files/workpackage1/nki.pdf 
Mobile DL with PDAs: Development and testing of pedagogical and system solutions supporting mobile distance learners

Rekkedal \& Dye

Dye, A., \& Rekkedal, T. (2005). Testing of an "always-online mobile environment." Evaluation paper for the project, mLearning, the Next Generation of Learning. Retrieved June 26, 2006 from: http://learning.ericsson.net/mlearning2/files/workpackage6/testing.doc

Fagerberg, T., Rekkedal, T., \& Russell, J. (2002). Designing and Trying Out a Learning Environment for Mobile Learners and Teachers. Sub-project of the EU Leonardo project, From e-Learning to m-Learning. Retrieved June 27, 2006 from: http://www.nettskolen.com/forskning/55/NKI2001m-learning2.html

Fritsch, H. (2002). mLearning for Smartphones. Conference presentation at mLearning: The Cutting Edge. November 11, Dublin, Ireland. Retrieved June 7, 2006 from: http://learning.ericsson.net/mlearning2/project_one/presentation/helmut1911.ppt

Gamlin, M. (1995). Distance Learning in Tranisition: The Impact of Technology: A New Zealand perspective. Keynote address to 1995 EDEN Conference: The Open Classroom, Distance Learning, and New Technologies in School Level Education and Training. September 18-20. Oslo, Norway.

Leonardo Da Vinci Project (n.d.). European Commission Leonardo Da Vinci project website. Retrieved April 17, 2007 from: http://ec.europa.eu/education/programmes/leonardo/leonardo_en.html

Marton, F., Dahlgren, L. O., Svensson, L. \& Säljö, R. (1987). Inlärning och omvärldsuppfatning [in Swedish]. Stockholm: Almquist \& Wiksell. 6. opplag.

Marton, F., Hounsell, D., \& Entwistle, N. (1997). The Experience of Learning. Implications for Teaching and Studying in Higher Education. Edinburgh: Scottish Academic Press.

Morgan, A. (1993). Improving Your Students' Learning: Reflections on the experience of study. London: KoganPage.

Mortensen, I. (2003). Universell tilrettelegging av nettbasert studium i 'Ledelse og organisasjon' [in Norwegian]. Bekkestua: NKI. Retrieved June 27, 2006 from: http://www.nettskolen.com/forskning/soffrapport_universell.pdf

NKI (2005). Strategisk plan for NKI Fjernundervisning 2005-2007 [in Norwegian]. Internal document. Bekkestua: NKI.

Paulsen, M. F. (2006). COGs, CLIPs and Other Instruments to Support Cooperative Learning in Virtual Environments. Paper presented at the 4th EDEN Research Workshop, Research into online distance education and e-learning, 25-28 October. Barcelona, Spain, 2006. Selected papers (in print) from the workshop.

Paulsen, M. F., Fagerberg, T., \& Rekkedal, T. (2003). Student Support Systems for Online Education available in NKI's Integrated Systems for Internet Based E-learning. Oslo: NKI. Retrieved June 27, 2006 from: http://learning.ericsson.net/socrates/doc/norwayp3.doc 
Mobile DL with PDAs: Development and testing of pedagogical and system solutions supporting mobile distance learners

Rekkedal \& Dye

Rekkedal, T. (1990). Recruitment and Study Barriers in the Electronic College. In M. F. Paulsen \& T. Rekkedal (Eds.) The Electronic College: Selected Articles from the EKKO project. Bekkestua: NKI/ SEFU.

Rekkedal, T. (1998). Courses on the WWW: Student Experiences and Attitudes Towards WWW Courses. An evaluation report written for the Leonardo Online Training Project. Retrieved June 27, 2006 from: http://www.nki.no/eeileo/research/eei/Rekkeval.htm

Rekkedal, T. (1999). Courses on the WWW: Student Experiences and Attitudes Towards WWW Courses, II. Evaluation report written for the Leonardo On-line Training Project, MMWWWK. Retrieved June 27, 2006 from: http://www.nki.no/eeileo/research/Rekkedalcorrected.html

Rekkedal, T. (2002a). Enhancing the Flexibility of Distance Education - Experiences with a Learning Environment for Mobile Distance Learners. Paper presented at the mLearning: The Cutting Edge conference. November 22, Dublin, Ireland. Retrieved June 26, 2006 from: http://learning.ericsson.net/mlearning2/project_one/presentation/torstein1911.ppt

Rekkedal, T. (2002b). Trying Out a Learning Environment for Mobile Learners. Evaluation of the course "The Tutor in Distance Education" - Phase 1 of the NKI sub-project of the EU Leonardo Project 'From e-learning to m-learning.' July 2002. Retrieved June 26, 2006 from: http://learning.ericsson.net/mlearning2/project_one/NKI2001mlearningevaluationFinal.doc

Rekkedal, T. (2002c). Trying Out a Learning Environment for Mobile Learners II Evaluation of the course "Online Teaching and Learning" - Phase 2 of the NKI sub-project of the EU Leonardo Project 'From e-learning to m-learning.' Retrieved June 262006 from: http://learning.ericsson.net/mlearning2/project_one/student_use_year_2_nki.doc

Rekkedal, T., \& Paulsen, M. F. (1997). The Third Generation NKI Electronic College. A Survey of Student Experiences and Attitudes. An evaluation report written for the Leonardo Online Training Project, MMWWWK. Retrieved 27, 2006 from: http://www.nki.no/eeileo/research/nki/evaluati.htm

Russell, J. (2005). SMS, the in house development experience. (Unpublished technical working paper) Oslo: NKI Distance Education.

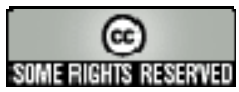

